\title{
Estudos de usuários da informação sob a perspectiva das práticas informacionais*
}

\section{Andrea Heloiza Goulart}

Maestría en Ciencia de la Información, Universidad de Brasília, Brasil, 2018. Postgraduada en Mercadeo, Escuela Superior de Propaganda y Mercadeo, Brasil, 2002. Pregrado en Comunicación Social, Universidad Anhembi Morumbi, Brasil, 1995. Doctoranda en Ciencia de la Información en la Universidad de Brasília, Brasil. andreagoulart@gmail.com https://orcid.org/0000-0002-9778-1661

\section{Ivette Kafure}

Doctora en Ciencia de la Información, Universidad de Brasília, Brasil. Maestría en Informática en la Universidad Federal de Campina Grande, Brasil. Especializada en Pedagogía de la Cooperacióny Metodologías Colaborativas en la Universidad de la Paz(Unipaz) en colaboración con la Universidad Paulista (Unip), DF, Brasil. Especialización en Prácticas Audiovisuales en la Universidad del Valle, Cali, Colombia. Ingeniera de Sistemas de la Universidad Autónoma de Manizales, Manizales, Colombia. Profesora de la Facultad de Ciencia de la Información de la Universidad de Brasília, Brasil. ivettek@unb.br http://orcid.org/0000-0002-5758-8226

\begin{abstract}
Resumo
O artigo caracteriza brevemente os estudos de usuários, na Ciência da Informação para, em seguida, expor os paradigmas da Ciência da Informação e relacioná-los com as diferentes abordagens empregadas nos estudos de usuários da informação. Por ter seu foco voltado para o prisma social e para a perspectiva das práticas informacionais, o texto detalha tais conceitos e apresenta três exemplos de pesquisas desenvolvidas sob esta ótica. Finalmente, são discutidas as formas como os aludidos conceitos podem ser aplicados na prática..
\end{abstract}

Palavras-chave: estudos de usuários, abordagem social, práticas informacionais, busca de informação na vida cotidiana.

Cómo citar este artículo: Goulart, Andrea; Kafure, Ivette (2021). Estudos de usuários da informação sob a perspectiva das práticas informacionais. Revista Interamericana de Bibliotecología, 44(3), e334004. https://doi.org/10.17533/udea.rib.v44n3e334004

Recibido: 2018-07-10 / Aceptado: 2021-08-19

* Este artículo hace parte de la investigación de la tesis de maestría sustentada en el año 2018, títulada "Adolecencia, Internet y Prácticas Informacionales" en la Universidad de Brasília (UnB), como uno de los requisitos para la obtención del título de magíster de la autora Andrea Heloiza Goulart, teniendo como directora a la profesora Ivette Kafure. El trabajo completo se encuentra publicado en el Repositório Institucional de la Universidad de Brasília y está disponible en https://repositorio.unb.br/handle/10482/32018 


\section{User Information Studies in the Perspective of Informational Practices}

\begin{abstract}
The article briefly characterizes user studies in Information Science and goes on to set out the Information Science paradigms and relate them to the different approaches employed in the studies of information users. With its focus on the social prism and the perspective of informational practices, the text goes deeper into these concepts and presents three examples of research developed in this light. Finally, the ways in which these concepts can be applied in practice are discussed.
\end{abstract}

Keywords: Study of users, social approach, information practices, everyday life information seeking.

\section{Estudios de usuarios a partir de la perspectiva de las prácticas informacionales}

\section{Resumen}

Este artículo caracteriza de manera breve los estudios de usuarios en la ciencia de la información. Expone los paradigmas de esta ciencia y los relaciona con los diferentes abordajes empleados en los estudios de usuarios de la información. Al tener su enfoque orientado hacia el prisma social y en la perspectiva de las prácticas informacionales, el texto detalla tales conceptos y presenta tres ejemplos de investigaciones desarrolladas a partir de está óptica. Finalmente, examina cómo dichos conceptos pueden ser puestos en práctica.

Palabras clave: estudios de usuarios, práctica social, prácticas informacionales, búsqueda de información en la vida cotidiana.

\section{Introdução}

A Ciência da Informação, por ser uma ciência social e humana, com um objeto de estudo complexo, apresenta diferentes interpretações (Rendón-Rojas, 2012). O mesmo ocorre com os estudos de usuários, que têm evoluído ao longo do tempo. Para Matta (2010) "tão importante quanto estudar o objeto "informação" é o estudo daqueles que a utilizam” (p. 130). Capurro (2003), apresenta três paradigmas para a Ciência da Informação que podem ser relacionados às diferentes abordagens que marcam os estudos de usuários: a tradicional, a alternativa e a social (Araújo, 2012).

O presente artigo expõe a relação entre os paradigmas apresentados por Capurro (2003) e os diferentes enfoques dos estudos de usuários, com especial atenção à abordagem social e à perspectiva das práticas informacionais. Com isso, são evidenciados três estudos de busca de informação na vida cotidiana, como forma de ilustrar as possibilidades oferecidas às pesquisas que se desenvolvem sob a ótica das práticas informacionais.

\section{Estudos de usuários da informação}

Estudos de usuários visam descobrir quais informações são buscadas pelos sujeitos e se as necessidades informacionais dos usuários de uma biblioteca ou de um centro de informação têm sido adequadamente satisfeitas. Assim, busca-se descobrir porque, como e para qual finalidade os indivíduos usam a informação (Figueiredo, 1994). De acordo com Cunha, Amaral e Dantas (2015), tais investigações envolvem todos os tipos de necessidades, demandas, expectativas, atitudes e demais práticas a respeito do uso da informação pelo indivíduo.

Neste sentido, Sanz-Casado (1993) apresenta cinco objetivos dos estudos de usuários: 1) conhecer hábitos e necessidades dos usuários, a fim de tornar os centros de informação mais adequados às suas carências; 2) tornar os centros de informação capazes de atender a um maior número de demandas; 3) oferecer treinamento aos usuários, de modo a conhecer seus hábitos e necessidades; 4) identificar, nos sistemas de informação, os pontos fracos que necessitam de reforma; e 5) conhecer os grupos de pesquisa, com o propósito de fornecer a informação necessária e de forma eficiente.

Araújo (2009; 2016) esclarece que as primeiras pesquisas neste campo foram os estudos de comunidade que, na década de 1930, investigavam, sob uma perspectiva funcionalista, as características de certo grupamento humano, com o objetivo de oferecer aos integrantes 
informações adequadas para a sua educação e a sua socialização. Em seguida, no final da década de 1940, foram desenvolvidos os estudos de uso, cujo objetivo era de aferir o grau de satisfação dos usuários e também de oferecer feedback aos sistemas. Nestes casos, os usuários eram estudados sob uma perspectiva sistêmica.

Em 1966, a publicação, no Annual Review of Information Science and Technology, de um capítulo sobre necessidades e usos de informação auxiliou na estruturação do referido campo de pesquisa e fez com que o tema viesse a integrar os programas de graduação e pós-graduação em Arquivologia, Biblioteconomia e Ciência da Informação (Araújo, 2016).

Outro marco relevante para os estudos de usuários ocorreu em 1996, por ocasião do primeiro Information Seeking in Context (ISIC), evento bienal que, atualmente, é denominado The Information Behaviour Conference. Neste e em outros colóquios chegou-se ao entendimento de que é possível verificar a ocorrência histórica de três grandes perspectivas para estudos de usuários da informação: 1) os estudos de uso, surgidos na década de 1930; 2) os estudos de comportamento informacional, cuja origem remonta ao final da década de 1970 e 3) os estudos das práticas informacionais, iniciados em meados da década de 1990 (Araújo, 2016).

Assim, é possível estabelecer relação entre os paradigmas da Ciência da Informação, elaborados por Capurro (2003), e as distintas abordagens dos estudos de usuários (Araújo, 2010a; Araújo, 2010b; Gandra \& Duarte, 2012): a abordagem tradicional, que envolve os estudos de uso, corresponde ao paradigma físico; a abordagem alternativa, representada pelos estudos de comportamento informacional, relaciona-se ao paradigma cognitivo e a abordagem social, caracterizada pelos estudos das práticas informacionais, está ligada ao paradigma social.

\section{Os paradigmas da ciência da informação e as abordagens dos estudos de usuários}

Capurro (2003) apresenta três paradigmas dominantes na Ciência da Informação: 1) o físico, 2) o cognitivo e 3) o social. Para o autor, o início da disciplina, em meados do século XX, é marcado pelo paradigma fisico, o qual, posteriormente, seria contestado pela perspectiva cognitiva idealista e individualista, sendo esta sucedida pelo paradigma pragmático e social.

No paradigma físico, a mensagem ou informação que o emissor transmite ao receptor equivale a um objeto físico, o que aproxima este modelo da teoria matemática da comunicação de Shannon e Weaver (1974) e da cibernética de Norbert Wiener (1961). Na Ciência da Informação, o paradigma físico impulsionou experimentos de medição de resultados de sistemas computadorizados de recuperação de informação, como os estudos de Cranfield, de 1957, e colocou o usuário como receptor passivo no processo de recuperação da informação. Assim, esta teoria desconsidera o papel ativo do usuário no processo informativo e comunicativo (Capurro, 2003).

No que diz respeito aos estudos de usuários, o paradigma físico liga-se à abordagem tradicional, na qual a informação é entendida como objeto dotado de propriedades objetivas, não apresentando relação com o usuário. O campo tem caráter empirista e emprega, principalmente, métodos quantitativos, a fim de averiguar padrões e regularidades no comportamento dos usuários. (Araújo, 2010a).

Em oposição à perspectiva física, surge o paradigma cognitivo, influenciado pela ontologia de Karl Popper (1973), estudioso que postulou a existência de três mundos: 1) o físico, formado pelos objetos; 2) o da consciência, caracterizado pelo pensamento e 3) o do conhecimento objetivo, composto pelos elementos do mundo dois (consciência humana) transformados em elementos do mundo um (objetos físicos), mas que, devido à sua natureza particular, compreenderiam um mundo à parte (Capurro, 2003; Araújo, 2012). Na Ciência da Informação, o mundo três de Popper, do conhecimento objetivo, foi associado ao conceito de informação por autores como Belkin e Brookes, que principiaram uma linha de estudos cognitivos da informação (Araújo, 2012).

Segundo Capurro (2003), em tais estudos, a busca de informação é desencadeada no momento em que o sujeito percebe uma lacuna de conhecimento, ou estado cognitivo anômalo, em que o conhecimento ao seu alcance não basta para solucionar determinado problema. 
O autor, contudo, aponta limites do paradigma cogni tivo, por esta abordagem enxergar a informação como algo distinto do sujeito e entender o usuário como sujeito cognoscente, não visualizando o indivíduo como ser social.

Em relação aos estudos de usuários, pode-se afirmar que o paradigma cognitivo se relaciona com a abordagem alternativa, que intenta investigar a forma como o sujeito busca e usa a informação para suprir uma lacuna de conhecimento (Araújo, 2012). Representada por autores como Dervin, Nilan, Belkin, Kuhlthau, dentre outros, a perspectiva alternativa desenvolveu o modelo de comportamento informacional, que objetiva compreender como o usuário reage ao perceber uma lacuna de conhecimento e o que faz para suprir tal deficiência (Araújo, 2012). Segundo Wilson (1999), o comportamento informacional compreende as atividades nas quais as pessoas se engajam ao identificarem necessidades de informação.

A fim de suprir deficiências do modelo cognitivo, Capurro (2003) apresenta o paradigma social, que agrega o contexto social à perspectiva individualista do paradigma cognitivo e é representado por autores como Frohmann, Hjorland, Brier e o próprio Capurro. Nesta ótica, "a informação é vista como uma construção social, algo que é definido no terreno da ação concreta de sujeitos em ações recíprocas (isto é, interações), tal como no contexto das "comunidades discursivas" (Araújo, 2012, p. 146).

De acordo com Araújo (2010b), o marco histórico deste paradigma acontece em 1991, na Finlândia, no I CoLIS (International Conference on Conceptions of Library and Information Science), ocasião em que pesquisadores de todo o mundo questionaram os modelos seguidos pela Ciência da Informação até aquele momento, ao passo que apresentaram novas propostas de pesquisa.

No que se refere aos estudos de usuários, o terceiro paradigma alinha-se à abordagem social, surgida a partir das críticas ao modelo alternativo, que enfatiza o cognitivismo, desconsiderando o contexto social dos usuários (Araújo, 2010b; Araújo, 2016). Assim, alternativamente ao conceito de comportamento informacional, surge o conceito de práticas informacionais. Desenvolvida por autores como Savolainen, McKenzie, Tuominen e Talja, esta abordagem busca contextualizar o indivíduo socialmente (Araújo, 2016; Savolainen, 2007).

Vale ressaltar, todavia, que tanto a abordagem do comportamento informacional como a das práticas informacionais objetivam compreender as relações entre o sujeito e a informação. O que diferencia as duas perspectivas é o modo como tratam a problemática em questão: enquanto os estudos de comportamento informacional abordam o sujeito cognitivo motivado por uma lacuna informacional, as pesquisas sob a ótica das práticas informacionais concentram-se nas práticas coletivas e sociais, contemplando contextos acadêmicos, laborais, de aprendizagem em local de trabalho e de vida cotidiana (Rocha, Duarte \& Paula, 2017).

\section{A perspectiva das práticas informacionais}

Partidário da perspectiva das práticas informacionais, Savolainen (2007) argumenta que, nos estudos de informação, conceitos de "comportamento informacional" e "práticas informacionais" são usados para caracterizar o modo como as pessoas lidam com a informação. Tais concepções, entretanto, provêm de diferentes discursos e abrem pontos de vista alternativos nas relações do sujeito com a informação. O autor esclarece que os estudos de práticas informacionais se apoiam, principalmente, nas ideias do construcionismo social e compreendem os indivíduos como membros de grupos e comunidades. Com isso, as pesquisas sob esta ótica levam em conta os fatores contextuais de busca, uso e compartilhamento da informação.

O construcionismo social enfatiza os processos linguísticos, substituindo o conceito de cognição por conversas. Nesta perspectiva dialógica, o mundo social, o conhecimento e as identidades são constituídos por conversas, com o uso do idioma. Assim, o construcionismo pressupõe que os limites do conhecimento social são definidos por discursos, uma vez que as práticas discursivas categorizam o mundo e fornecem uma pers pectiva para que o conhecimento seja produzido. Assim, o contexto de uso da linguagem é enfatizado, visto que os significados das palavras nem sempre permanecem estáveis (Talja, Tuominen \& Savolainen, 2005). 
De acordo com Talja (1997), as necessidades de informação individual, bem como o acesso à informação institucional são condicionados socialmente. Deste modo, as pesquisas de informação do ponto de vista cognitivo, que analisam como o indivíduo processa a informação individualmente, não oferecem soluções para o estudo do contexto sociocultural dos processos de informação. $\mathrm{O}$ autor defende a preponderância de uma perspectiva analítica do discurso, em que o contexto sociocultural dos processos de informação se localiza em discursos, que oferecem diferentes entendimentos para a construção e a sistematização do conhecimento.

A análise do discurso sob a abordagem construcionista centra seu foco nos modos como as narrativas são construídas para parecerem factuais, bem como nas funções discursivas que elas devem exercer. Assim, uma narrativa não é vista simplesmente como uma representação realista dos processos cognitivos, mas dependente da função que pretende desempenhar, como para convencer, defender, culpar (McKenzie, 2003).

Para McKenzie (2003), os modelos baseados na abordagem cognitiva são úteis para descrever buscas de informações em ambientes acadêmicos ou de trabalho, uma vez que, normalmente, lidam com uma única necessidade, sem levar em conta a variedade de comportamentos de informação que fazem parte da vida diária dos indivíduos. Sob este prisma, o conceito de prática desvia o foco do sujeito individual para enquadrar o indivíduo como membro simultâneo de diversos grupos e comunidades, que constituem o contexto de suas atividades mundanas. Desta forma, a abordagem das práticas informacionais acentua o fato de as atividades moldadas por fatores socioculturais se desenvolverem de forma contínua e rotineira (Savolainen, 2007).

De acordo com Rocha et al. (2017), os estudos de comportamento informacional são, geralmente, direcionados a contextos científicos e profissionais. As relações entre sujeito e informação, contudo, não acontecem apenas em tais contextos. Com isso, as pesquisas de práticas informacionais também evidenciam a vida cotidiana, o encontro causal de informação e a busca de informação sem a consciência de uma lacuna informacional, ampliando assim os horizontes de pesquisa.
McKenzie (2003) esclarece que as buscas de informação cotidianas envolvem uma série de práticas que podem ser tanto premeditadas quanto casuais. Assim, o indivíduo pode buscar um conteúdo ativamente, para atender a uma necessidade conhecida, ou pode deparar-se com uma fonte inesperada, um fato novo ou uma situação familiar que o ajudem a atender a alguma necessidade presente ou futura.

Alguns estudos neste sentido são apresentados a seguir, a fim de ilustrar os conceitos explanados.

\subsection{A busca de informação na vida cotidiana}

Savolainen (1995) alega que investigações sobre necessidades, busca e uso de informações relacionadas ao campo profissional acabaram ofuscando o estudo das práticas de informação não relacionadas às atividades laborais, embora este tipo de análise também esteja associado a atividades importantes. Assim, o autor propõe o estudo da busca de informação na vida cotidiana (Everyday Life Information Seeking - ELIS).

O modelo proposto por Savolainen (1995) encontra seu referencial teórico na Teoria do Habitus, desenvolvida por Pierre Bourdieu (1984). Por ela, o habitus equivale a um sistema social e culturalmente determinado de pensamento, percepção e avaliação, já presente na consciência do indivíduo. A Teoria do Habitus equivale, portanto, a um sistema relativamente estável, pelo qual indivíduos logram integrar o conjunto de suas experiências e valorar a pertinência das escolhas a que procederam em seu dia-a-dia. Deste modo, o habitus revela as escolhas que seriam naturais ou esperadas, relativamente a uma classe social ou a um grupo cultural (Savolainen, 1995). A Figura 1 apresenta o modelo Everyday Life Information Seeking (ELIS).

O ELIS, tal como proposto por Savolainen (1995), implica no uso de conceitos de 1) modo de vida e 2) domínio da vida para o subsequente exame das questões relativas à busca de informação. O l) modo de vida vincula-se à "ordem das coisas", que se baseiam nas escolhas pessoais de cada um de nós, na vida cotidiana. O conceito de "coisas" aproxima-se das inúmeras atividades corriqueiras e "ordem" é a escala de preferência atribuída a tais atividades (Savolainen, 1995). 
VIDA COTIDIANA

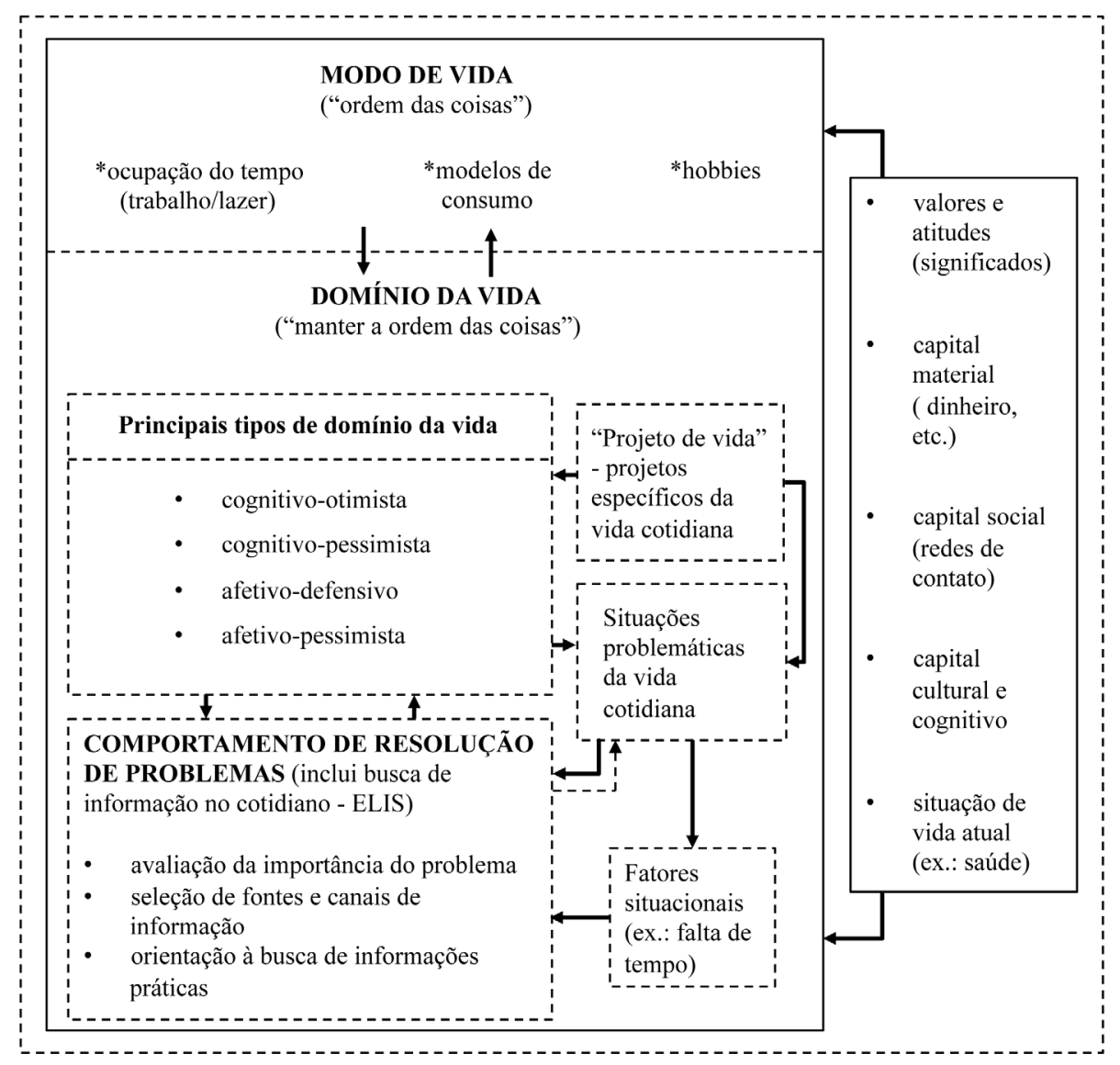

Figura 1. Modelo ELIS.

Fuente: adaptado de Savolainen (1995).

Quanto ao 2) domínio da vida, é relativo à preparação para a solução de problemas cotidianos, de modo que as coisas sigam ordenadas. É em tal contexto que a busca de informação assume um papel de relevo (Rocha et al., 2017). Os tipos de domínio da vida são quatro: o a) cognitivo-otimista, que se caracteriza pela crença em resultados positivos para a solução de problemas; o b) cognitivo-pessimista, em que a possibilidade de um problema não ser resolvido é admitida; o c) afetivo-defensivo, que se apoia em visões positivas acerca das chances de solução do problema, e o d) afetivo-pessimista, em que o sujeito não acredita nas suas habilidades para resolver algum problema e não se habilita a envidar esforços para melhorar a situação na qual se encontra (Savolainen, 1995).

Os domínios da vida guardam correspondência com o comportamento de resolução de problemas, inclusive a busca de informação para o cotidiano, abrangendo três diferentes estágios: 1) avaliação da importância do problema; a 2) seleção de fontes e 3) canais de informação e orientação à busca de informações práticas. Também recebem influência dos projetos de vida, das situações problemáticas do cotidiano e dos fatores situacionais. Cabe acrescentar que o modelo trabalha com valores e atitudes; capital material; capital social; capital cultural e cognitivo e situação de vida atual, ou seja, todo um conjunto de fatores que influenciam, a um só tempo, o modo de vida e o domínio de vida (Savolainen, 1995).

Baseado em tais premissas, Savolainen (1995) desenvolveu estudo empírico, aplicado a dois grupos de profissionais com níveis de educação formal distintos (trabalhadores de indústria e professores), para identificar o modo como se procedia a busca de informação no cotidiano dos integrantes de ambos. A conclusão a 
que se chegou é que o modo de vida influencia as práticas de busca de informação e é por elas influenciado. Além da reciprocidade revelada, o tipo de domínio da vida afeta os modos pelos quais os indivíduos se aproximam dos problemas cotidianos e levantam informações práticas para facilitar o encaminhamento da problemática e a sua consequente solução.

Conforme asseveram Cunha et al. (2015), o modelo em causa "enfatiza o papel dos fatores sociais e culturais que afetam a preferência e o uso das fontes de informação" (p. 1ll). Rocha et al. (2017) consideram que o emprego do estudo de Savolainen auxilia nas pesquisas de práticas informacionais, uma vez que ilumina a noção de vida cotidiana e também a influência dos fatores sociais, culturais, individuais e temporais na relação das pessoas com a informação.

\subsection{Modelo bidimensional de práticas informacionais}

A partir da perspectiva de busca de informação cotidiana, de Savolainen (1995), McKenzie (2003) desenvolveu um estudo qualitativo com 19 mulheres, com idades variando entre 19 e 40 anos, todas grávidas de gêmeos. A pesquisadora empregou entrevistas iniciais semiestruturadas e entrevistas retrospectivas em profundidade, de modo a examinar as práticas informacionais, as necessidades de informação e as fontes utilizadas pelas futuras mães. O estudo considerou as formas como as entrevistadas construíam suas narrativas de busca de informações, bem como o modo como elas utilizavam estes discursos para representar a si mesmas de maneira particularizada, a fim de observar a variedade de práticas informacionais descritas pelas respondentes.

Durante a pesquisa, McKenzie (2003) concluiu que o termo "comportamento informacional" é inadequado para descrever as práticas que compunham as narrativas das participantes do estudo, visto que este conceito implica na busca ativa de informações, num contexto de identificação de uma carência informacional, o que requer foco cognitivo e envolve ação por parte do indivíduo. No entanto, as participantes da pesquisa, muitas vezes, relataram a ocorrência de recuperação de informações sem que a busca fosse ativa. Assim, a autora argumenta que o foco nas práticas, e não no comportamento, muda a investigação do cognitivo para o social e o uso do termo "práticas informacionais" engloba todo o espectro de elementos que envolvem as narrativas: tanto aquelas que se enquadram na definição de comportamento informacional, de Wilson (1999), como aquelas informações que chegam por outros meios (McKenzie, 2003). Depois de analisar as múltiplas práticas informacionais das entrevistadas, a pesquisadora desenvolveu um modelo bidimensional, apresentado na Figura 2.

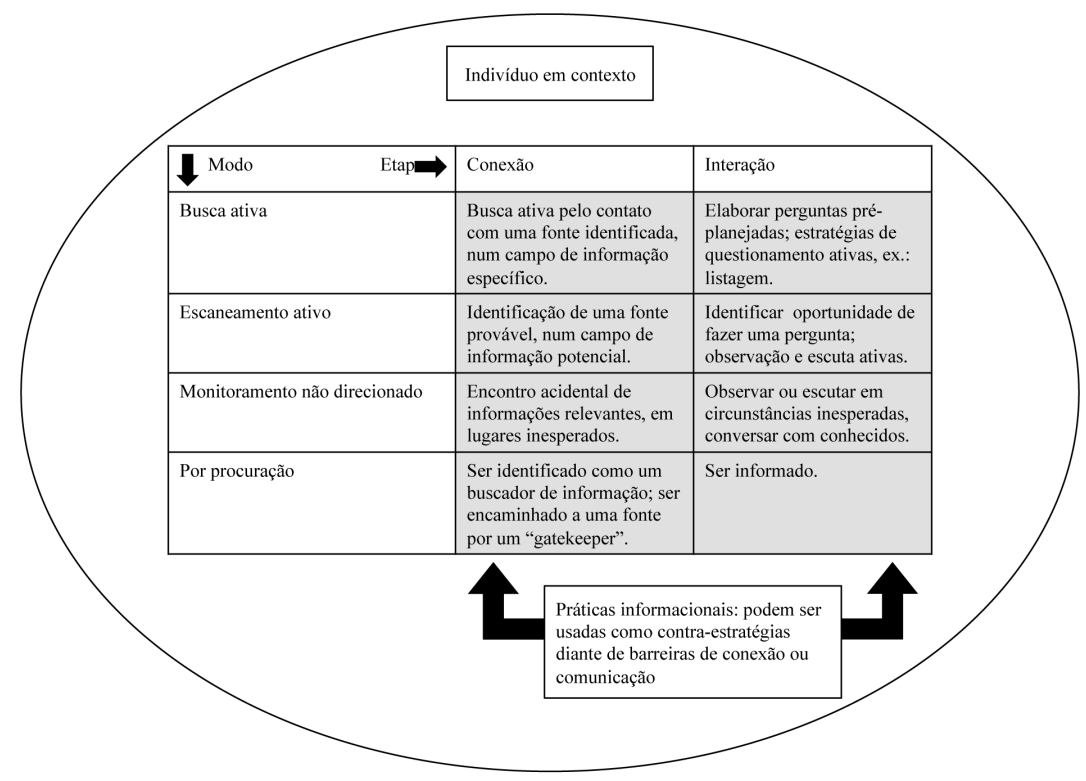

Figura 2. Modelo bidimensional de práticas informacionais.

Fuente: adaptado de McKenzie (2003). 
McKenzie (2003) considera duas etapas do processo de informação: conexão e interação. O modelo combina ambas as fases com quatro modos de práticas informacionais: busca ativa, escaneamento ativo, monitoramento não direcionado e por procuração. A combinação destas fases permite a descrição de alterações no modo de busca de informação à medida que o processo informacional é desenvolvido.

A busca ativa envolve práticas informacionais direcionadas, como a busca de uma fonte previamente conhecida, a realização de uma pesquisa sistemática e de itens conhecidos, a elaboração de perguntas planejadas antecipadamente e o emprego de estratégias ativas de questionamento. O escaneamento ativo compreende práticas semidirecionadas, como a busca de informações em lugares prováveis, a identificação de oportunidades para fazer perguntas espontâneas, bem como a observação e a audição ativas sobre o assunto de interesse. O monitoramento não direcionado consiste no encontro acidental de informações relevantes e o reconhecimento de uma fonte em um lugar improvável, num momento em que não havia qualquer busca ativa ou intenção de encontrar tal informação. Finalmente, a busca por procuração diz respeito aos momentos em que os participantes encontram fontes de informação por intermédio de outro agente, ou gatekeeper (McKenzie, 2003).

Além disso, as etapas do modelo descrevem dois estágios no processo informacional: conexão e interação. A primeira considera as barreiras e as práticas envolvidas na identificação e no contato com as fontes, seja diretamente ou com o auxílio de um intermediário. Já a interação contempla as práticas envolvidas durante o encontro de uma fonte de informação, bem como estratégias para enfrentar as barreiras existentes no processo (McKenzie, 2003).

De acordo com Savolainen (2007), o modelo desenvolvido por McKenzie enfatiza as práticas sociais e as interações pessoais em contextos da vida cotidiana, ampliando o escopo das práticas informacionais para além dos limites dos estudos de comportamento informacional.
4.3 Modelo de necessidades informacionais cotidianas de adolescentes urbanos

Tomando por base o modelo ELIS, de Savolainen (1995), Agosto e Hughes-Hassell (2006a) desenvolveram estudo sobre as necessidades informacionais cotidianas dos adolescentes urbanos e o eventual atendimento de tais necessidades. A pesquisa tinha por meta a determinação das fontes de consulta e dos tipos de mídia de uso mais frequente pelos jovens, no processo de busca de informação na vida cotidiana (ELIS), e resultou em dois modelos, um de perfil teórico e outro de caráter empírico.

Na construção do modelo teórico, as autoras levantaram dados sobre as necessidades informacionais gerais, o comportamento de busca de informações cotidianas e o uso da internet pelos adolescentes, mediante um conjunto de entrevistas com 27 jovens. Por esta via, des velaram sete áreas de desenvolvimento da adolescência e concluíram que a busca de informação cotidiana (ELIS) do adolescente está centrada na coleta de infor mações que facilitem o processo de amadurecimento do jovem. Nesse sentido, a busca de informação cotidiana (ELIS) auxilia os usuários na interpretação do mundo à sua volta e no estabelecimento da posição que nele ocupam, fato que contribui para o desenvolvimento social, emocional, reflexivo, físico, criativo, cognitivo e sexual dos jovens. No modelo, cada uma das sete variáveis diz respeito a um subconjunto da compreensão progressiva que o adolescente tem de si mesmo e do mundo ao seu redor. Não obstante, as variáveis trabalhadas sofrem influência da situação pessoal e também do ambiente cultural de cada indivíduo (Agosto \& Hughes-Hassell, 2006a). O modelo teórico de Agosto e Hughes-Hassell está retratado na Figura 3.

Para a definição do modelo empírico, as pesquisadoras somaram, aos sete componentes aludidos do modelo teórico, um mosaico de 28 tópicos relativos às necessidades de informação derivadas da análise de dados, em um amplo conjunto temático que abrange as questões de interesse dos adolescentes na busca ativa de informações e os temas acerca dos quais gostariam de se informar (Agosto \& $\mathrm{Hu}$ ghes-Hassell, 2006b). A Figura 4 expõe o modelo empírico de Agosto e Hughes-Hassell. 


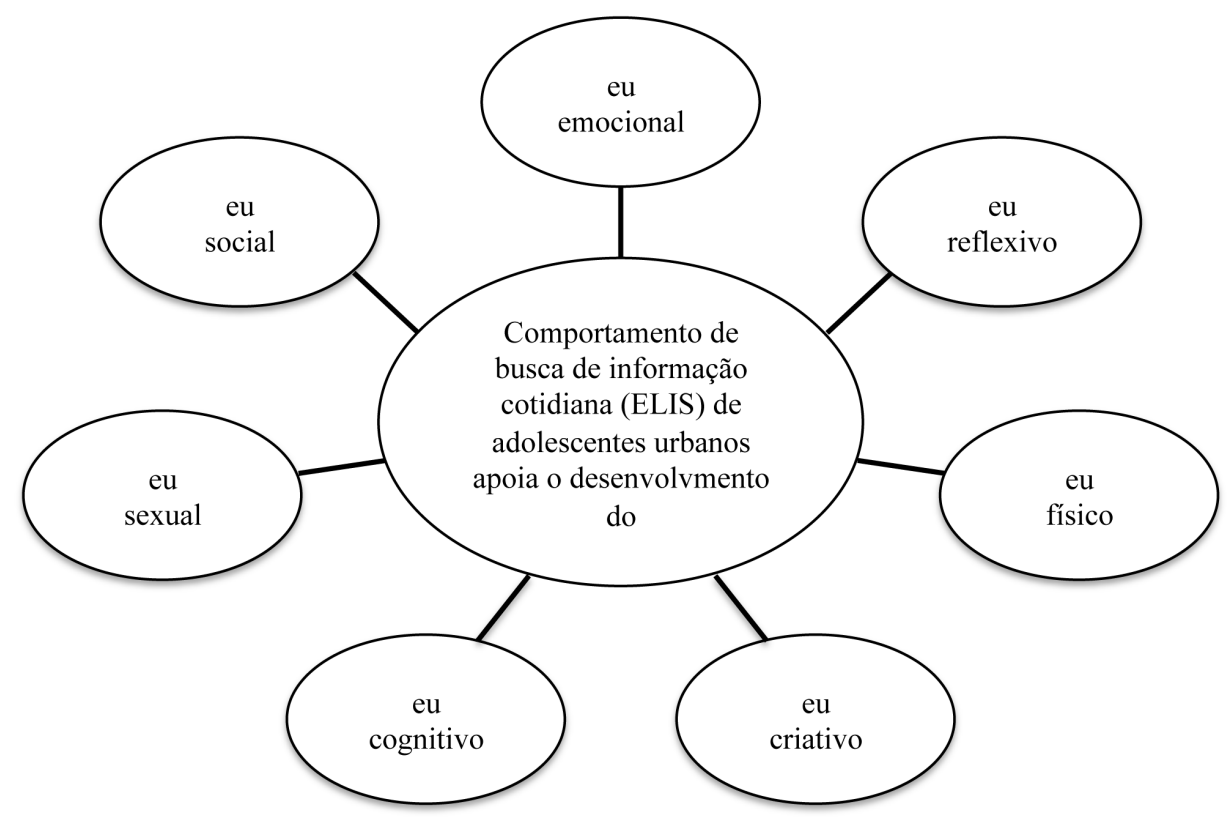

Figura 3. Modelo teórico de desenvolvimiento dos adolescentes urbanos.

Fonte: adaptado de Agosto e Hughes-Hassell (2006a).

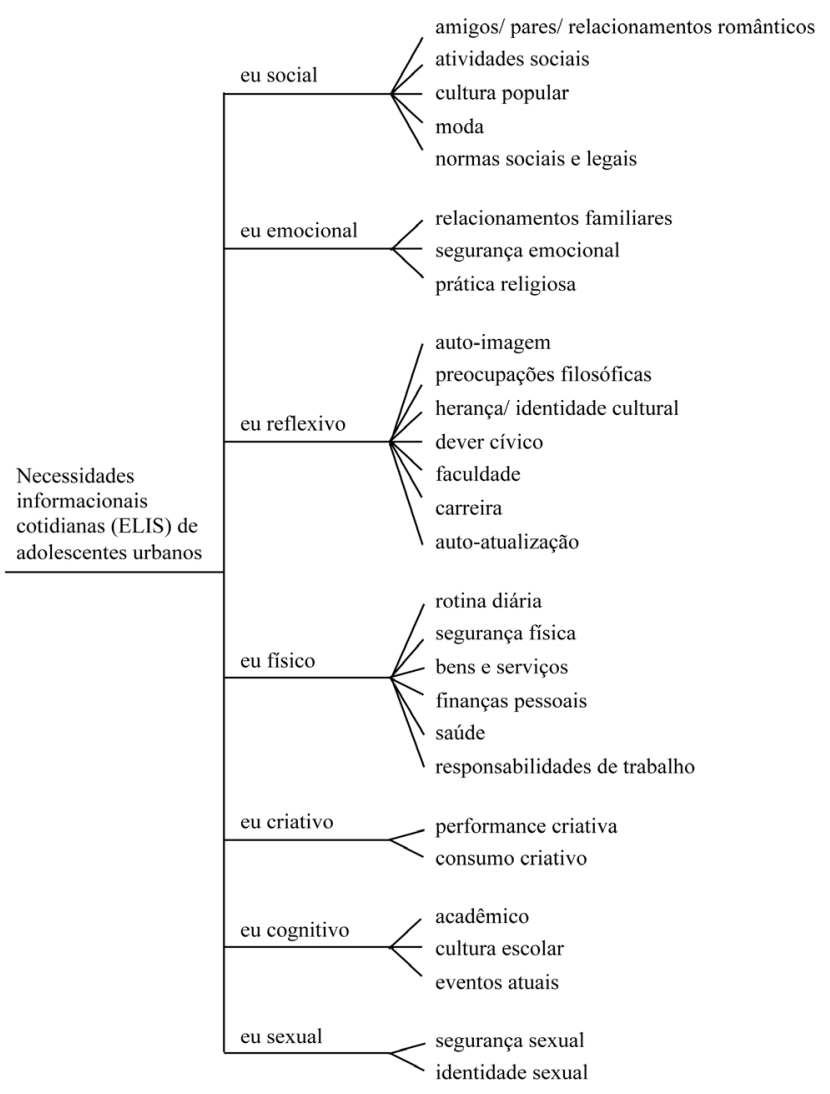

Figura 4. Modelo empírico de necesidades informacionais cotidianas de adolescentes urbanos

Fonte: adaptado de Agosto e Hughes-Hassell (2006b).
O estudo reiterou algumas revelações de pesquisas anteriores sobre o tema, ampliando a compreensão sobre as necessidades informacionais cotidianas dos adolescentes urbanos (Agosto \& Hughes-Hassell, 2006b). Pode-se notar, portanto, que os modelos auxiliam na correlação entre as práticas informacionais dos jovens e as necessidades que este público manifesta em seu progressivo amadurecimento.

\section{Conclusão}

Todas as três abordagens dos estudos de usuários (a tradicional, a alternativa e a social) ainda são utilizadas e têm seu lugar, muito embora cada uma atenda a objetivos diversos e circunscritos de pesquisa. Enquanto a ótica tradicional privilegia, no mais das vezes, a geração de dados quantitativos, que auxiliam no diagnóstico de serviços e sistemas de informação, os prismas alternativo e social têm sua atenção voltada para o sujeito, ainda que conservando formas distintas de enxergar os indivíduos (Araújo, 2016).

O presente artigo concede maior atenção à abordagem social e à perspectiva das práticas informacionais, a fim de evidenciar uma alternativa de pesquisa àqueles que acreditam que as abordagens tradicional e alternativa não bastam para abarcar toda a complexidade existente nas relações entre o indivíduo e a informação. 
Os exemplos apresentados revelam formas distintas de se proceder ao estudo de usuários sob a perspectiva das práticas informacionais, em especial à investigação sobre a busca de informações cotidianas. Com isso, pretende-se mostrar como tais estudos podem ser conduzidos na prática, uma vez que, segundo Araújo (2016), muitas vezes, os pesquisadores enfrentam dificuldades para aplicar estes conceitos, de caráter mais abstrato.

Abordar o indivíduo dentro de seu contexto sociocultural, levando em consideração não apenas as informações buscadas ativamente, mas também aquelas que são encontradas casualmente, sem dúvida é uma tarefa árdua e complexa. Esta perspectiva, no entanto, é capaz de enriquecer e valorar o entendimento das relações entre o sujeito e a informação.

\section{Referências}

1. Agosto, Denise; Hughes-Hassell, Sandra (2006a). Toward a model of the everyday life information needs of urban teenagers, part l: Theoretical model. Journal of the American SocietyforInformationScienceandTechnology,57(10),1394-1403. https:/onlinelibrary.wiley.com/doi/full/10.1002/asi.2045l

2. Agosto, Denise; Hughes-Hassell, Sandra (2006b). Toward a model of the everyday life information needs of urban teenagers, part 2: Empirical model. Journal of the American Society for InformationScience and Technology, 57(11), 1418-1426. https://onlinelibrary.wiley.com/doi/10.1002/asi.20452

3. Araújo, Carlos (2009). Correntes teóricas da ciência da informação. Ciência da Informação, 38(3), 192-204. http://www.scielo.br/pdf/ci/v38n3/v38n3al3.pdf

4. Araújo, Carlos (2010a). Estudos de usuários conforme o paradigmasocialdaciênciadainformação:desafiosteóricos epráticos de pesquisa. Informação đ Informação, 15(2), 23-39. https://brapci.inf.br/index.php/res/v/32439

5. Araújo, Carlos (2010b). Abordagem interacionista de estudosdeusuáriosdainformação.PontodeAcesso,4(2), 2-32. https://brapci.inf.br/index.php/res/v/81528

6. Araújo, Carlos (2012). Paradigma social nos estudos de usuários da informação: abordagem interacionista. Informação ơ Sociedade: Estudos, 22(1), 145-159. https://periodicos.ufpb.br/ojs/index.php/ies/article/ view/9896

7. Araújo, Carlos (2015). Imaginação e Sociabilidade: Novos Conceitos para o Estudo de Usuários da Informação. XVI Encontro Nacional de Pesquisa em Ciência da Informação, João Pessoa, Brasil, 26-30 de outubro. http://www.ufpb.br/evento/index.php/enancib2015/ enancib2015/paper/viewFile/2981/1045

8. Araújo, Carlos (2016). Estudos de usuários da informação: comparação entre estudos de uso, de comportamento e de práticas a partir de uma pesquisa empírica. Informação $\mathrm{em}$ Pauta, 1(1), 61-78. http://www.periodicos.ufc.br/informacaoempauta/ article/view/2970

9. Bourdieu, Pierre (1984). Distinction: a social critique of the judgement of tast. London: Doutledge.

10. Capurro, Rafael (2003). Epistemologia e Ciencia da Informacao. $V$ Encontro Nacional de Pesquisa em Ciência da Informação. Belo Horizonte, MG. http://www.capurro.de/enancib_p.htm

11. Cunha, Murilo; Amaral, Sueli; Dantas, Edmundo (2015) Manual de Estudo de Usuários da Informação. São Paulo: Atlas.

12. Figueiredo, Nice (1994). Estudos de uso e usuários da informação. Brasília: IBICT.

13. Gandra, Tatiane; Duarte, Adriana (2012). Estudos de usuários na perspectiva fenomenológica: revisão de literatura e proposta de metodologia de pesquisa. Informação e Sociedade: Estudos, 22(3), 13-23. https://brapci.inf.br/index.php/res/v/101880

14. Matta, Rodrigo (2010). Modelo de comportamento informacional de usuários: uma abordagem teórica. Em Marta Valentin (Org.), Gestão, mediação e uso da informação (pp. 127-142). São Paulo: Cultura Acadêmica. https://static.scielo.org/scielobooks/j4gkh/pdf/ valentim-9788579831171.pdf

15. McKenzie, Pamela (2003). A model of information practices in accounts of everyday-life information seeking. Journal of Documentation, 59(1), 19-40.

16. Popper, Karl (1973). Objective Knowledge. An Evolutionary Approach. Oxford: Clarendon Press.

17. Rendón-Rojas, Miguel Ángel (2012). Epistemologia da Ciência da Informação: objeto de estudo e principais categorias. InCID: Revista de Ciência da Informação e Documentação, 3(1), 3-14.

18. Rocha, Janicy Aparecida Pereira; Duarte, Adriana Bogliolo Sirihal; Paula, Claudio Paixão Anastácio de (2017). Modelos de práticas informacionais. Em Questão, 23(1), 36-61.

19. Sanz-Casado, Elías (1993). La realización de estudios de usuários: una necesidad urgente. Revista General de Información y Documentación, 3(1), 154-163. 
http://revistas.ucm.es/index.php/RGID/article/view/ RGID9393120155A/11793

20. Savolainen, Reijo (1995). Everyday life information seeking: Approaching information seeking in the context of "way of life". Library $\Theta$ information science research, 17(3), 259-294.

21. Savolainen, Reijo (2007). Information behavior and information practice: Reviewing the "umbrella concepts" of information-seeking studies. The Library Quarterly, 77 (2), 109-132.

22. Shannon, Claude; Weaver, Warren (1964). The mathematical theory of communication. The University of Illinois Press: Urbana.

23. Talja, Sanna (1997). Constituting "information" and "user" as research objects: a theory of knowledge formations as an alternative to the information-man theory. Em Vakkari, P., Savolainen, R., \& Dervin, B. (Orgs.). Information seeking in context (pp. 67-80). Londres: Taylor Graham.

24. Talja, Sanna; Tuominen, Kimmo, Savolainen, Reijo. (2005). "Isms" in information science: constructivism, collectivism and constructionism. Journal of Documentation, 6l(1), 79-101.

25. Wiener, Norbert (1961). Cybernetics or control and communication in the animal and the machine. Cambridge, Massachusetts: MIT. Press.

26. Wilson, Tom (1999). Models in information behaviour research. Journal of Documentation, 55(3), 249-70. https://doi.org/10.1108/EUM0000000007145 